\title{
Disgust and Sexual Arousal in Young Adult Men and Women
}

Citation for published version (APA):

Grauvogl, A., de Jong, P., Peters, M., Evers, S., van Overveld, M., \& van Lankveld, J. (2015). Disgust and Sexual Arousal in Young Adult Men and Women. Archives of Sexual Behavior, 44(6), 1515-1525. https://doi.org/10.1007/s10508-014-0349-4

Document status and date:

Published: 01/01/2015

DOI:

10.1007/s10508-014-0349-4

Document Version:

Publisher's PDF, also known as Version of record

Document license:

Taverne

Please check the document version of this publication:

- A submitted manuscript is the version of the article upon submission and before peer-review. There can be important differences between the submitted version and the official published version of record.

People interested in the research are advised to contact the author for the final version of the publication, or visit the DOI to the publisher's website.

- The final author version and the galley proof are versions of the publication after peer review.

- The final published version features the final layout of the paper including the volume, issue and page numbers.

Link to publication

\footnotetext{
General rights Owners
rights.

- You may freely distribute the URL identifying the publication in the public portal. please follow below link for the End User Agreement:

www.umlib.nl/taverne-license

Take down policy

If you believe that this document breaches copyright please contact us at:

repository@maastrichtuniversity.nl

providing details and we will investigate your claim.
}

Copyright and moral rights for the publications made accessible in the public portal are retained by the authors and/or other copyright owners and it is a condition of accessing publications that users recognise and abide by the legal requirements associated with these

- Users may download and print one copy of any publication from the public portal for the purpose of private study or research.

- You may not further distribute the material or use it for any profit-making activity or commercial gain

If the publication is distributed under the terms of Article $25 \mathrm{fa}$ of the Dutch Copyright Act, indicated by the "Taverne" license above, 


\title{
Disgust and Sexual Arousal in Young Adult Men and Women
}

\author{
Andrea Grauvogl $\cdot$ Peter de Jong $\cdot$ Madelon Peters $\cdot$ Silvia Evers $•$ \\ Mark van Overveld · Jacques van Lankveld
}

Received: 6 May 2013 / Revised: 5 April 2014 / Accepted: 13 June 2014 / Published online: 18 September 2014

(C) Springer Science+Business Media New York 2014

\begin{abstract}
Previous research suggested that disgust may interfere with healthy sexual functioning by demonstrating that women with sexual pain disorders are characterized by heightened disgust propensity, relatively strong (physiological and subjective) disgust responses when exposed to sexual stimuli, and relatively strong automatic sex-disgust memory associations. To broaden the understanding of the relationship between sex and disgust, Study 1 tested the relationship between trait disgust and sexual functioning in both men $(N=109)$ and women $(N=187)$, and showed that specifically for women both relatively high disgust propensity and high sensitivity were related to lower sexual functioning. Study 2 focused on healthy young adults $(N=19$ men and $N=24$ women), and tested the relationship between trait disgust and automatic sex-disgust associations as well as the predictive value of trait disgust propensity for participants' level of sexual arousal while watching an erotic video. Participants completed a single-target Implicit Association Task and self-
\end{abstract}

A. Grauvogl $(\bowtie) \cdot$ M. Peters

Faculty of Psychology and Neuroscience, Maastricht University, PO Box 616, 6200 MD, Maastricht, The Netherlands e-mail: Andrea.Grauvogl@maastrichtuniversity.nl

\section{P. de Jong}

Faculty of Behavioral and Social Sciences, University of Groningen, Groningen, The Netherlands

\section{S. Evers}

Faculty of Health, Medicine and Life Sciences, Maastricht

University, Maastricht, The Netherlands

M. van Overveld

Rotterdam School of Management, University of Rotterdam, Rotterdam, The Netherlands

J. van Lankveld

Faculty of Psychology, Open University of the Netherlands, Heerlen, The Netherlands report measures of trait disgust propensity, disgust sensitivity, and sexual functioning. Furthermore, genital and subjective sexual arousal was measured, while participants were watching neutral and erotic video clips. Women showed stronger sex-disgust associations and reported higher disgust propensity than men. Overall, indices of trait disgust and sex-disgust associations were not strongly associated with sexual functioning or sexual arousability. Unexpectedly, specifically in men, high levels of trait disgust sensitivity predicted higher levels of genital and subjective sexual arousal. Overall, no strong evidence was found to support the view that, among young adults without sexual difficulties, high trait disgust or relatively strong automatic sex-disgust associations are associated with low sexual functioning and low sexual arousal.

Keywords Sexual arousal · Disgust · Young adults . Implicit measures $\cdot$ Explicit measures

\section{Introduction}

Sexual dysfunctions are characterized by the persistent or recurrent disturbance of the sexual response to erotic stimuli. They cause distress for the individual and the partner. The current DSM-5 classification distinguishes the following dysfunctions in females: female orgasmic disorder, female sexual interest/ arousal disorder, genito-pelvic pain/penetration disorder, and in males: delayed ejaculation, erectile disorder, male hypoactive sexual desire disorder, and premature (early) ejaculation (American Psychiatric Association, 2013). Sexual dysfunctions are an important public health concern as approximately $40 \%$ of women and $30 \%$ of men experience sexual problems (Laumann, Paik, \& Rosen, 1999), of whom a substantial proportion also experience distress. There is considerable evidence that cognitive processes linked to fear and pain may be involved in 
the development of sexual problems (Barlow, 1986; Janssen \& Everaerd, 1993; Payne, Binik, Amsel, \& Khalifé, 2005). Recently, it has been argued that, next to fear, disgust may also be involved in the development of sexual dysfunctions (Borg, de Jong, \& Weijmar-Schultz, 2010; de Jong \& Peters, 2009; de Jong, van Overveld, \& Borg, 2013; de Jong, van Overveld, Weijmar Schultz, Peters, \& Buwalda, 2009).

It has been proposed that disgust has evolved as a first line of defense to protect humans from contamination by infectious agents (Oaten, Stevenson, \& Case, 2009). Because disgust elicits the urge to withdraw from the disgusting cue, it facilitates the avoidance of physical contact with pathogens. In line with such a disease-avoidance conceptualization, disgust is typically focused on the intersection between the body and the environment and concentrates on the skin and body apertures (Rozin, Nemeroff, Horowitz, Gordon, \& Voet, 1995). Sexual behavior represents an obvious threat for the transmission of disease. The close physical contact, body apertures, and exchange of bodily fluids that are implied in sexual behavior provide ample opportunity for the transmission of pathogens. Accordingly, there are many aspects of sexual behaviors that may promote the generation of disgust. Because of its critical features, disgust thus seems an obvious candidate for being involved in the inhibition of sexual responses. To the extent that disgust-induced sexual inhibition more chronically outbalances the propensity for sexual excitation, this may give rise to various sexual problems and promotes the development of sexual dysfunctions (de Jong et al., 2013).

In line with the idea that disgust might be involved in sexual dysfunctions, it has been found that women with vaginismus show enhanced automatic sex-disgust associations and facial expressions of disgust (as indexed by facial muscular activity in the levator labii regions) when exposed to sex stimuli (Borg et al., 2010). Subsequent research corroborated these findings by showing that women with vaginismus are characterized by heightened self-reported disgust for sexual contaminants (van Overveld et al., 2013).

Although these earlier studies provided evidence to suggest that enhanced sexual disgust is involved in sexual dysfunctions, it remains to be tested whether (1) this relationship between enhanced sexual disgust and (poor) sexual functioning represents a general phenomenon that can also be found among people without sexual difficulties and (2) whether enhanced sexual disgust might indeed compromise the generation of "healthy" sexual responses. As a first step to examine the alleged inhibitory influence of disgust on sexual arousal, the present study was designed to test whether people who show relatively strong automatic disgust associations with sexual stimuli display relatively weak sexual arousal when viewing an erotic video.

In addition, if indeed disgust is an important factor in the generation of sexual problems, individuals with enhanced trait disgust might be at risk for developing sexual problems. In this respect, it is important to differentiate between a generally heightened liability to respond with the emotion of disgust (disgust propensity), and the tendency to find the emotion of disgust unpleasant (disgust sensitivity) (van Overveld, de Jong, Peters, Cavanagh, \& Davey, 2006). Both disgust propensity and sensitivity have been shown to be independently related to individuals' responses to stimuli that are potentially disgust-provoking (de Jong \& Peters, 2009; de Jong et al., 2009; van Overveld et al., 2006). Consistent with the view that high disgust propensity may be considered as a latent vulnerability factor for developing sexual dysfunctions, it has been shown that women with vaginismus displayed enhanced disgust propensity compared to women without sexual problems (de Jong et al., 2009). Meanwhile, it remains to be explored whether people suffering from sexual dysfunction also show enhanced disgust sensitivity.

To further explore the alleged role of enhanced trait disgust in lowering the threshold for developing sexual problems, the present study examined whether heightened disgust propensity and/or sensitivity is associated with low sexual functioning among people without sexual difficulties. In order to examine this, additional analyses were performed using the data from an earlier study of van Overveld et al. (2013) (Study 1), in which the association between disgust and sexual functioning was examined in a large student sample. The relationship between trait disgust and sexual functioning was also examined in the group of participants who were specifically invited for the present study (Study 2). From the perspective that high trait disgust would affect sexual functioning via lowering the threshold for sexual stimuli to acquire disgust-evoking properties, we also investigated whether people with relatively high trait disgust would show relatively high levels of sexual disgust as reflected in the automatic sex-disgust associations. Moreover, we tested whether participants with high levels of trait disgust would show less sexual arousal when watching an erotic video than individuals with relatively low levels of disgust propensity and/or disgust sensitivity.

The present study included men and women without sexual difficulties. Because previous studies predominantly focused on women with sexual dysfunctions, it remains to be determined whether high levels of state or trait disgust are also associated with compromised sexual functioning in a non-clinical population. Moreover, there may be gender differences with regard to the influence of disgust on sexual functioning as previous research found that sexual disgust and willingness to handle sexually contaminated stimuli were associated with sexual functioning in women, but not in men (van Overveld et al., 2013). Moreover, we included both explicit (DS-R and DPSS-R) and implicit (stIAT) measures of disgust. Previously, a dissociation was found between implicit and explicit affective responses to pictures of sexual intercourse in women with sexual pain disorder (dyspareunia or vaginismus); whereas on the explicit level they reported negative associations to sex cues, their automatic or implicit associations were positive (Brauer, de Jong, Huiding, 
Laan, \& ter Kuile, 2009; Huijding, Borg, Weijmar-Schulz, \& de Jong, 2011). Finally, we measured both subjective and genital arousal as indices of sexual functioning because individuals' subjective responding may diverge from their physiological responding when exposed to erotic stimuli (e.g., Chivers, Seto, Lalumière, Laan, \& Grimbos, 2010).

To conclude, the aim of this study was to investigate the relationships between trait disgust (as indexed by disgust propensity and disgust sensitivity), automatic sex-disgust associations, and sexual functioning in a sexually healthy group of young adults. We hypothesized that participants with relatively high self-reported disgust propensity or disgust sensitivity would exhibit relatively strong automatic sex-disgust associations, lower self-reported sexual functioning, and lower genital and/or subjective arousal during erotic stimulation.

\section{Study 1}

Method

\section{Participants}

The current study sample consisted of students from the schools of Health Sciences, Medicine and Psychology at Maastricht University ( $N=304 ; 63.2 \%$ women). Participants were recruited using posters and flyers at the faculty and invited to participate in a survey study on sex and sexual acts. The data for the present study were part of a larger experiment (see for a more elaborate description of the full study sample: van Overveld et al., 2013).

\section{Measures}

\section{Disgust Scale}

The Disgust Scale (DS; Haidt, McCauley, \& Rozin, 1994) is a 32-item self-report instrument, using a 5-point Likert scale, measuring disgust propensity (e.g., "It would bother me to see a rat run across my path in a park"). A high score signifies high disgust propensity (range, $0-25$ ). The internal consistency of the total scale has been shown to be good (Cronbach's $\alpha=.84$ ) (Haidt et al., 1994). Also in the current study $(\alpha=0.78)$, the internal consistency was satisfactory.

\section{Disgust Propensity and Sensitivity Scale-Revised}

The Disgust Propensity and Sensitivity Scale-Revised (DPSSR; Fergus \& Valentiner, 2009; van Overveld, De Jong, \& Peters, 2010) is a 12-item self-report instrument, using a 5-point Likert scale (range, 12-60), measuring disgust propensity (e.g., "I avoid disgusting things") and disgust sensitivity (e.g., "It scares me when I feel nauseous") irrespective of particular disgust elicitors. Psychometric evaluation demonstrated satisfactory internal consistency ( $\alpha=.89$ for propensity and $\alpha=.87$ for sensitivity) (van Overveld et al., 2006) and predictive validity (van Overveld et al., 2010). Also in the current sample, internal consistency was satisfactory for both disgust propensity $(\alpha=$ $0.81)$ and sensitivity $(\alpha=0.75)$.

\section{Female Sexual Function Index}

The female sexual function index (FSFI; Rosen et al., 2000) is a 19-item self-report instrument, using a 6-point Likert scale, which aims to measure sexual functioning on the dimensions of sexual desire, arousal, lubrication, orgasm, satisfaction, and pain. A high score indicates healthy sexual functioning (range, 2-36). High internal consistency was demonstrated for all subscales in sexually dysfunctional $(\alpha=.82-.93)$ and healthy women (.83-.95). Test-retest reliability was satisfactory for all subscales in both groups $(r=.68-.80$ and $r=.77-.91$, respectively) (Rosen et al., 2000). The internal consistency in the current sample, based on the total scale, was excellent $(\alpha=.97)$.

\section{International Index of Erectile Function}

The international index of erectile function (IIEF; Rosen et al., 1997) is a 15-item self-report instrument, using a 6-point Likert scale, which aims to measure male sexual functioning on the dimensions of erectile functioning, orgasmic functioning, sexual desire, intercourse satisfaction, and overall satisfaction. A high score indicates healthy erectile functioning (range, 8-75). Internal consistency $(\alpha=.92)$ and test-retest reliability have been shown to be high ( $r=.84$; Rosen et al., 1997). The internal consistency in the current sample, based on the total scale, was excellent $(\alpha=.96)$.

Procedure

Upon their consent to participate in the study, participants received a package containing Dutch versions of the DPSS-R, DS, IIEF, and FSFI. Next, arrangements were made with the experimenter to return the booklet. Participants were offered either the opportunity to complete it in the privacy of their own home or in small groups at a conference room in our department. Participants were informed that, upon completion of the booklet, they would enter a lottery where they could win 50 euros (see for more information: van Overveld et al., 2013).

\section{Results}

To investigate whether disgust was associated differently with sexual functioning in men versus women, Pearson bivariate correlations were examined between indices on trait disgust (DPSS-R, DS) and sexual functioning (IIEF for men, FSFI for women). Eight participants did not complete the index on sexual 
Table 1 Bivariate Pearson correlations between trait disgust (DPSS-R, DS) and sexual functioning (FSFI) in women $(N=187)$

\begin{tabular}{lllr}
\hline FSFI & DPSS-R (propensity) & DPSS-R (sensitivity) & \multicolumn{1}{c}{ DS } \\
\hline Sexual desire & -.07 & -.11 & .03 \\
Arousal & -.11 & -.13 & -.08 \\
Lubrication & -.11 & -.13 & -.09 \\
Orgasm & $-.18^{*}$ & $-.15^{*}$ & -.13 \\
Satisfaction & -.11 & -.12 & -.07 \\
Pain & $-.20^{* *}$ & $-.15^{*}$ & -.09 \\
Total score & $-.18^{*}$ & -.13 & -.12 \\
\hline
\end{tabular}

FSFI female sexual functioning index, DPSS-R disgust propensity and sensitivity scale-revised, $D S$ disgust scale

** Significant at $p<.01 ; *$ Significant at $p<.05$

Table 2 Bivariate Pearson correlations between trait disgust (DPSS-R, DS) and sexual functioning (IIEF) in men $(N=109)$

\begin{tabular}{llll}
\hline IIEF & $\begin{array}{l}\text { DPSS-R } \\
\text { (propensity) }\end{array}$ & $\begin{array}{l}\text { DPSS-R } \\
\text { (sensitivity) }\end{array}$ & DS \\
\hline Erectile functioning & .10 & .03 & .06 \\
Orgasmic & .07 & .01 & .10 \\
$\quad$ functioning & & & .01 \\
Sexual desire & .17 & .08 & -.01 \\
Intercourse & .03 & .03 & -.05 \\
$\quad$ satisfaction & & & .02 \\
Overall satisfaction & -.06 & .02 & .05 \\
Total score & .05 & &
\end{tabular}

$I I E F$ international index of erectile function, DPSS-R disgust propensity and sensitivity scale-revised, $D S$ disgust scale

** Significant at $p<.01 ; *$ Significant at $p<.05$

functioning and were excluded from the current analyses. Tables 1 and 2 show that in women, subscales on ability to achieve orgasm and sexual pain demonstrated significant negative associations with disgust propensity (DPSS-R) and disgust sensitivity (DPSS-R). The FSFI total score showed a significant negative association with disgust propensity $(r=-.18 ; p=.02)$, while a similar but border significant association was observed with sensitivity $(r=-.13 ; p=.08)$. Although a similar pattern was evident for the DS, these relationships did not reach significance. This might well be due to the fact that the DS asks about disgust for specific stimuli which might not all be relevant for the participants thereby undermining its sensitivity as a more global measure of trait disgust propensity. All in all, trait disgust levels were associated negatively with sexual functioning for women, while for men, no significant associations were observed at all.

\section{Summary}

While for women, there was a negative relationship between trait disgust and sexual functioning, no such relationship was found for men. This suggests that the role of trait disgust on sexual (dys)functioning could be more relevant for women than for men.

\section{Study 2 \\ Method \\ Participants}

The study sample consisted of 19 male (age: $M=22.35$; $\mathrm{SD}=$ 1.66) and 24 female (age: $M=21.38 ; \mathrm{SD}=2.04$ ) heterosexual, Caucasian, students at Maastricht University, the Netherlands. Forty-three percent of the participants were single. All participants were sexually active, based on their affirmative answer to the question if they had been sexually active in the last 3 months. Participants were recruited using flyers and an internet site for students' research participation, inviting men and women between the age of 18 and 25 to categorize words and pictures and to watch erotic video clips while their genital and subjective sexual arousal would be measured. All participants had experience with sexual intercourse. Before students were invited to the lab, they were screened for the presence of scores in the clinical range that may reflect the presence of a sexual dysfunction (based on FSFI or IIEF score). For being allowed for the actual experiment, their FSFI score had to be $\geq 19$ (Rosen et al., 2000) and for the IIEF $\geq 45$ (Rosen et al., 1997), and sexually dysfunctional participants were thus excluded.

\section{Measures}

\section{Single-target Implicit Association Test (stIAT)}

To examine automatic disgust associations with sex cues, we used a single-target Implicit Association Test (stIAT) that was specifically designed for this study. This variant of the IAT (Greenwald, McGhee, \& Schwartz, 1998) is a computerized reaction time task that measures to what extent a single-target category is associated with two attribute categories (Wigboldus, Holland, \& van Knippenberg, 2005). In the current stIAT, the single-target category was sex, which was represented by pictures of heterosexual penetration (Borg et al., 2010). The attribute categories were "disgust" (represented by the words sweat, stench, bad breath, excrements, garbage, and intestines) and "nice" (represented by the words ice cream, pastry, perfume, chocolate, lovely, and appealing). To enable participants to become familiar with the procedure, the stIAT started with a practice run in which the participant had to categorize only the attribute words. Next, there were two blocks of 60 trials each preceded by a practice block of 30 trials. In one block, sex pictures and disgust-related words were mapped on the same response key whereas in the other block sex pictures and positive valence words shared the same response key. To prevent 
response bias, correct responses of the test blocks were divided equally over the two response keys (Bluemke \& Fiedler, 2009). The order of presentation of both phases was counterbalanced across participants.

Participants categorized words and pictures that appeared in the middle of a computer screen using two response keys. The labels of the categories assigned to these keys ("nice" and "disgust") were presented in the upper left and right corners of the screen. Following a correct response, the next stimulus was presented. Following an incorrect response, for pictures as well as attribute words, the word "false" appeared, and the stimulus remained on the screen until the correct response was given.

Because performance is expected to be better when the association between the target and the attribute is compatible with the participant's representational network than when this association is incompatible, one of both combinations (either the combination "sex" and "nice" or "sex" and "disgust") typically leads to faster and more accurate performance compared to the other.

To index the non-automatic (deliberate, explicit) subjective evaluation of the sex pictures, a visual analog scale ranging from -3 (not arousing) to +3 (very arousing) was used.

\section{Genital Sexual Arousal}

\section{Male Genital Sexual Arousal}

To measure male genital sexual responses, an electromechanical strain gage (Barlow, Becker, Leitenberg, \& Agras, 1970) was used. This device contains two arcs of surgical spring material joined with two mechanical strain gages, and produces changes in electrical resistance when the penis changes in circumference. The resistance changes are coupled, through a bridge circuit, to a BrainAmp ExG bio-amplifier (Brain Products) and an IBMcompatible computer. Participants positioned the gage on the midsection of the penile shaft with the gage part at the dorsal side. Calibration was performed before the beginning of every session using an oval device with six subsequent steps of 5-mm circumference increase each ranging from 90 to $125 \mathrm{~mm}$.

\section{Female Genital Sexual Arousal}

To measure female genital sexual responses, a vaginal photoplethysmograph (Hoon, Wincze, \& Hoon, 1976; Palti \& Bercovici, 1967; Sintchak \& Geer, 1975), a clear acrylic menstrual-tampon-shaped plastic probe with an embedded light source illuminating the anterior vaginal wall was used. An acrylic shield on the probe's cable determined depth of insertion and orientation. The probe could be easily self-inserted by the participant (Geer, 1983; Laan, Everaerd, \& Evers, 1995). The AC component of the signal of the vaginal photoplethysmograph was used to measure vaginal pulse amplitude (VPA; Laan et al.,
1995). Heart rate was measured to find valid peaks and troughs to be used as reference to detect VPA responses. For this purpose, three disposable ECG electrodes were placed on the female participant's chest, one at the sternum, one at the left side of the body on the last rib, and one at the lower back. VPA and ECG signals were recorded using a BrainAmp ExG bio-amplifier (Brain Products) and an IBM-compatible computer. The male and female genital probe disinfection procedure adhered to the pertinent local guideline.

\section{Subjective Sexual Arousal}

To measure subjective sexual arousal, participants used a lever mounted on a small plastic box that could be moved horizontally along a sliding scale. The extreme left position on the scale represented "not aroused" and the extreme right position "fully aroused." The lever position was displayed on the computer screen in front of the participant. Dots appeared incrementally (ranging from 0 to 10) at the bottom of the screen when the participants moved the dial to the right and disappeared when the participant moved the dial back to the left. The dots were presented just below the erotic video clip, so that the participants could keep their gaze fixed to the stimulus while they monitored their subjective sexual arousal. The lever signal was amplified using a BrainAmp ExG bio-amplifier and converted to a 0-100 scale. This task does not interfere with genital arousal, except when genital sexual arousal is very low (Wincze, Vendetti, Barlow, \& Mavissakalian, 1980).

\section{Self-Report Measures}

The same measures were used as in study 1 . However, in the present study, the Disgust Scale-Revised was used instead of the DS. The Disgust Scale-Revised (DS-R; van Overveld, de Jong, Peters, \& Schouten, 2011) is a 25-item self-report instrument, using a 5-point Likert scale, measuring disgust propensity (e.g., "It would bother me to see a rat run across my path in a park"). A high score signifies high disgust propensity (range, 2-24). The internal consistency of the total scale has been shown to be good (Cronbach's $\alpha=.87$ ) (van Overveld et al., 2011). The internal consistency in the present sample is poor (Cronbach's $\alpha=.57$ ).

With respect to the DPSS-R (range, 24-59), the internal consistency in the present sample is $\operatorname{good}(\alpha=.84$ for propensity and $\alpha=.77$ for sensitivity). With respect to the FSFI (range, 1936), the internal consistency in the current sample, based on the total scale, is excellent ( $\alpha=.96$ ). With respect to the IIEF (range, 45-75), the internal consistency in the current sample, based on the total scale, is excellent $(\alpha=.95)$.

\section{Video Material}

Four video clips were used which were presented in a fixed order. Participants first watched a 10 min clip with non-sexual 
content, followed by a 5 min erotic video clip. This sequence was then repeated using different video clips. The non-sexual baseline video clips were fragments of the BBC "Earth" series, presenting animals and flowers without any arousing content. The erotic video clips were fragments of a pornographic film, depicting petting, cunnilingus, fellatio, and penile-vaginal intercourse of a male and female actor couple. Close-ups of penile-vaginal intercourse and vaginal lubrication were also presented. The content of the video material was comparable to that of the stIAT pictures.

The order of the video clips was fixed. All videos were English spoken, and presented in full color with HD-resolution on a 17 " TFT-monitor.

\section{Procedure}

The study was evaluated and approved by the Ethics Committee of Maastricht University. The experiment took place in a sound attenuated room, separated from the experimenter's room by a door. Before arrival at the laboratory, participants filled in the FSFI or IIEF. Upon arrival at the laboratory, the participants were fully informed about the procedure of the experiment, were prompted for questions, and were reminded that they could stop with the experiment at any time. If the participant had no further questions, they were asked to read and sign an informed consent form. For female participants (because ECG electrodes were only used in women), a female researcher placed the ECG electrodes. If there were no more questions, the researcher left the room, closed the door, and further contact was continued over the intercom.

First, the participants performed the stIAT. After completion, all stIAT sex pictures were rated for arousal using the VAS. Next, participants placed the genital probe in the proper position without the researcher being present. All participants then covered their lap with a towel, to make them feel more comfortable and to eliminate visual cues of their genital sexual arousal (Wincze et al., 1980). If the probe was placed correctly the video fragments were started. The participants were instructed to use the lever during the erotic clips to report their subjective sexual arousal. After the last video clip, the participant removed the genital probe, and redressed before the researcher entered the room to remove the ECG electrodes. Finally, the participants completed the remaining questionnaires on the computer. The participant was then debriefed, given the opportunity to ask remaining questions, thanked, and received a $€ 25$ gift voucher for participation.

\section{Data Reduction and Analysis}

In line with previous research, the stIAT effect was calculated based on attribute trials only (Borg et al., 2010). Following the recommendations of Greenwald et al. (2003), reaction times (RTs) higher than $10,000 \mathrm{~ms}$ were discarded and error trials were replaced with the mean RT of the correct responses in the block in which the error occurred, plus a $600 \mathrm{~ms}$ penalty. The stIAT effect was calculated by subtracting the mean RT of the test block in which sex and nice shared the response button from the mean RT of the test block in which sex and disgust were mapped on the same key. In line with the widely used scoring algorithm (D600 measure) proposed by Greenwald et al. (2003), this difference score was divided by the pooled standard deviation based on all responses of the particular blocks. Consistent with previous sIAT research (e.g., de Hullu, de Jong, Sportel, \& Nauta, 2011), practice trials were discarded from the analyses, because we considered these trials to be truly practice. Thus, the lower the stIAT effect, the stronger the automatic sex-disgust association.

Genital sexual arousal data were saved and visually inspected off-line to detect and delete movement artifacts. Male response recordings were stored after conversion from $\mathrm{mV}$ to $\mathrm{mm}$ circumference change, based on the individual pre-session calibration data. Female response recordings (VPA data) were calculated in $\mathrm{mV}$. Data were averaged per $10 \mathrm{~s}$ epoch. We calculated both maximum and average responses based on the untransformed data of women and men separately. There were no differences between these two, thus only the average response will be reported. To calculate the genital response during the erotic video clip, all epochs from the onset of the erotic video clip through 300 s post-onset were included and compared with the average response during the last $90 \mathrm{~s}$ of the preceding neutral video clip. A mean score of the two erotic video clips was calculated. To render female and male genital sexual arousal data, comparable $z$-scores were calculated within participants using data of all $10 \mathrm{~s}$ epochs across the two erotic and two non-erotic film conditions, resulting in average $z$-scores with $M=0$, with $\mathrm{SD}=1$ for each participant (Chivers, Rieger, Latty, \& Bailey, 2004). ${ }^{1}$ Subjective sexual responses were averaged for both erotic video clips, and all epochs from video onset through $300 \mathrm{~ms}$ post-onset were included. Finally, a mean score of the two erotic video clips was calculated.

To answer the research questions, Pearson correlations were calculated between the stIAT score and explicit ratings of the arousing quality of the pictures, genital and subjective sexual arousal, disgust propensity (based on DS-R and DPSS-R) and disgust sensitivity (DPSS-R), and sexual functioning (based on FSFI and IIEF). Multiple hierarchical regression analyses were performed to examine whether the level of genital and subjective sexual arousal could be predicted by disgust propensity and disgust sensitivity (both measured with the DPSS-R), gender, and the interaction between disgust propensity and disgust sensitivity on the one hand and gender on the other.

\footnotetext{
${ }^{1}$ We have followed the method as described in Heiman (1977). We analyzed the genital data for men and women separately with this method using untransformed scores. These analyses demonstrated that the within sex analyses yielded similar results as when using $z$-scores. This gives us confidence that the pattern of results is not due to using $z$-scores.
} 
Table 3 Mean values for stIAT, arousal ratings of the stIAT pictures, sexual functioning (FSFI, IIEF), genital and subjective arousal during the erotic video clips, disgust propensity (DS-R and DPSS-R), and disgust sensitivity (DPSS-R), separately for men and women $(N=43$ )

\begin{tabular}{|c|c|c|c|c|c|c|c|c|}
\hline & \multicolumn{2}{|c|}{ Overall } & \multicolumn{2}{|c|}{ Men } & \multicolumn{2}{|c|}{ Women } & \multirow[t]{2}{*}{$t$} & \multirow[t]{2}{*}{$p$} \\
\hline & $\mathrm{M}$ & SD & $\mathrm{M}$ & SD & M & SD & & \\
\hline stIAT & .13 & .33 & .24 & .31 & 0.03 & .33 & 2.13 & $.039 *$ \\
\hline Arousal stIAT pictures & .96 & 1.2 & 1.1 & 1.0 & .89 & 1.3 & .456 & .651 \\
\hline Female sexual function index & & & & & 27.01 & 7.3 & & \\
\hline International index of erectile function & & & 54.45 & 19.86 & & & & \\
\hline Genital arousal video clip & & & $30.63^{\mathrm{a}}$ & 15.47 & $367.02^{\mathrm{b}}$ & 260.38 & & \\
\hline Subjective arousal video clip & 53.0 & 21.5 & 69.4 & 11.3 & 39.4 & 18.1 & 6.42 & $<.001 * *$ \\
\hline Disgust propensity (DS-R) & 1.7 & .42 & 1.6 & .43 & 1.9 & .39 & -2.17 & $.035^{*}$ \\
\hline Disgust propensity (DPSS-R) & 20.6 & 4.1 & 19.4 & 3.8 & 21.63 & 4.1 & -1.84 & .073 \\
\hline Disgust sensitivity (DPSS-R) & 15.4 & 3.6 & 15.0 & 3.5 & 15.7 & 3.8 & -.639 & .526 \\
\hline
\end{tabular}

\section{Results}

Table 3 presents the mean values of the descriptive variables, both for the whole group and for men and women separately. The stIAT score was significantly higher in men than in women. This means that women showed stronger automatic sex-disgust associations than men. Furthermore, women reported a stronger disgust propensity, as measured with the DS-R, than men.

The erotic video clips were successful in heightening sexual arousal. During the erotic clips, subjective arousal was higher in men than in women. The clips were also successful in eliciting genital arousal. The level of genital sexual arousal (men: penile circumference change in $\mathrm{mm}$; women: $\mathrm{mV}$ ) was higher during the erotic video clips (men: $M=43.37 ; S D=31.66$ and women: $M=784.15 ; S D=449.83$ ) than during the non-sexual baseline video clips (men: $M=16.74 ; S D=23.16$ and women: $M=$ 417.13; $S D=245.69)$. For both men and women, this difference was significant, $t(18)=8.85 ; p<.001$ and $t(23)=6.90 ; p<$ .001 , respectively.

Next, bivariate correlations were examined between indices of trait disgust (DPSS-R, DS-R) and sexual functioning (IIEF for men, FSFI for women), to investigate whether disgust was associated differently with sexual functioning in men versus women. Tables 4 and 5 show that in women, the subscale on pain experiences demonstrated a significant negative association with disgust propensity (DPSS-R).

Next, bivariate correlations were examined between the stIAT scores, sexual functioning and trait disgust. Overall, only the relationship between disgust sensitivity and disgust propensity (as indexed by both DPSS-R and DS-R) attained significance (see Table 6).

Next, correlations were calculated separately for women (Table 7) and men (Table 8). In women, the results indicated that genital arousal was negatively associated with subjective
Table 4 Bivariate Pearson correlations between trait disgust (DPSS-R, DS) and sexual functioning (FSFI) in women $(N=24)$

\begin{tabular}{llcc}
\hline FSFI & DPSS-R (propensity) & DPSS-R (sensitivity) & DS \\
\hline Sexual desire & -.03 & .19 & .13 \\
Arousal & -.08 & -.01 & .04 \\
Lubrication & -.10 & -.04 & .02 \\
Orgasm & -.06 & .04 & .07 \\
Satisfaction & -.06 & .17 & -.01 \\
Pain & $-.43 *$ & -.23 & -.38 \\
Total score & -.20 & -.04 & .03
\end{tabular}

FSFI female sexual functioning index, DPSS-R disgust propensity and sensitivity scale-revised, $D S$ disgust scale

* Significant at $p<.05$

arousal. Furthermore, there was no evidence to indicate that indices of trait disgust (DPSS-R, DS-R) and sexual disgust (stIAT) are strongly associated with sexual functioning or sexual arousability.

Also for men, there was no evidence indicating that indices of disgust were strongly associated with sexual functioning. However, as can be seen in Table 8, there was a significant correlation between sexual arousal during the erotic video clips (genital and subjective) and both indices of trait disgust. Yet, in contrast to our predictions, these positive correlations indicated that higher levels of trait disgust co-occurred with higher, instead of lower, sexual arousal.

In subsequent regression analyses, we tested whether the differential pattern of correlations between men and women reflected significant differences. In these analyses, genital and subjective arousal were used as the dependent variables, while gender, disgust propensity, disgust sensitivity, disgust propensity $\mathrm{x}$ gender, and disgust sensitivity $\mathrm{x}$ gender were used as 
independent variables. First, all predictor variables were entered. Next, if not significant, the interaction terms were deleted and the analysis was repeated with the variables that were retained. The final model is shown in Table 9, in which disgust sensitivity is presented. Although borderline is significant, the results indicate that a higher disgust sensitivity score could predict a higher level of genital sexual arousal.

For subjective arousal, gender and disgust propensity remained in the final equation indicating that, overall, women showed less subjective arousal, and that overall participants with high disgust propensity showed enhanced subjective sexual arousal (Table 10). Since none of the interaction terms remained in the equation, the regression analysis indicated that the relationship between disgust propensity and subjective arousal was not significantly stronger for men than for women.

In a final regression analysis, we examined whether disgust propensity and disgust sensitivity showed a (partly) independent relationship with genital and subjective arousal, both separately for men and women. The analysis showed that only

Table 5 Bivariate Pearson correlations between trait disgust (DPSS-R, DS) and sexual functioning (IIEF) in men $(N=19)$

\begin{tabular}{llll}
\hline IIEF & $\begin{array}{l}\text { DPSS-R } \\
\text { (propensity) }\end{array}$ & $\begin{array}{l}\text { DPSS-R } \\
\text { (sensitivity) }\end{array}$ & DS \\
\hline Erectile functioning & -.01 & -.17 & .13 \\
Orgasmic functioning & -.01 & -.07 & .24 \\
Sexual desire & .21 & .18 & .37 \\
Intercourse & .06 & -.12 & .29 \\
$\quad$ satisfaction & & & \\
Overall satisfaction & .01 & -.05 & .28 \\
Total score & .02 & -.13 & .24 \\
\hline
\end{tabular}

$I I E F$ international index of erectile function, DPSS-R disgust propensity and sensitivity scale-revised, $D S$ disgust scale

** Significant at $p<.01 ; *$ Significant at $p<.05$ disgust sensitivity had independent predictive value for both genital $(\beta=.615, p=.004)$ and subjective arousal $(\beta=.664$, $p=.001)$ in men. The positive beta values indicate that a higher level of disgust sensitivity was predictive of higher genital and subjective arousal. No significant results were found in women.

\section{Discussion}

The aim of this study was to investigate the association between disgust and sexual functioning in a sexually healthy group of female and male young adults, focusing on automatic sex-disgust associations and trait disgust. We hypothesized that participants with relatively high self-reported disgust propensity or disgust sensitivity would exhibit relatively strong automatic sex-disgust associations, lower sexual functioning, and lower genital as well as subjective arousal during erotic stimulation. The main results were that (1) women showed stronger automatic sex-disgust associations (stIAT) and stronger disgust propensity (DS-R) than men and (2) in men, higher levels of disgust sensitivity were predictive of higher levels of genital and subjective sexual arousal. We found no evidence that supports the view that relatively strong automatic sex-disgust associations would be linked with low sexual functioning in these participants.

With respect to the association between trait disgust and sexual functioning, the results of Study 1 and Study 2 were inconclusive. The results of both studies suggest that, for women, pain experiences during sexual activities were significantly negatively associated with disgust propensity. Furthermore, Study 1 identified that, for women, trait disgust was negatively associated with sexual functioning, and such associations were not observed for men. However, the results of Study 2 do not corroborate the suggestion that the role of trait disgust on sexual (dys)functioning would be more relevant for women than for

Table 6 Bivariate correlations of the total group

\begin{tabular}{|c|c|c|c|c|c|c|}
\hline stIAT & $\begin{array}{l}\text { Arousal stIAT } \\
\text { pictures }\end{array}$ & $\begin{array}{l}\text { Genital } \\
\text { arousal }\end{array}$ & $\begin{array}{l}\text { Subjective } \\
\text { arousal video }\end{array}$ & $\begin{array}{l}\text { Disgust } \\
\text { propensity } \\
\text { (DS-R) }\end{array}$ & $\begin{array}{l}\text { Disgust propensity } \\
\text { (DPSS-R) }\end{array}$ & $\begin{array}{l}\text { Disgust sensitivity } \\
\text { (DPSS-R) }\end{array}$ \\
\hline
\end{tabular}

stIAT

Arousal stIAT pictures $\quad-.14 \quad-$

Genital arousal

Subjective arousal video

$.12-.14$

Disgust propensity (DS-R)

Disgust propensity (DPSS-R) $\quad-.13 \quad-.04$

Disgust sensitivity (DPSS-R) $\quad .01 \quad .27$

Male SF $\quad-.24 \quad .20$

$-.16-.12$

$\begin{array}{rl}- & \\ -.05 & - \\ .15 & .04 \\ .17 & .03 \\ .29 & .14 \\ -.01 & .21 \\ .27 & .10\end{array}$

$\begin{array}{ll}- & \\ .72 * * & - \\ .50 * * & .59 * * \\ .24 & .02 \\ .03 & -.20\end{array}$

$S F$ sexual functioning

* Difference is significant at the .05 level (two-tailed); ** Difference is significant at the .01 level (two-tailed) 
Table 7 Bivariate correlations only for women

\begin{tabular}{|c|c|c|c|c|c|c|c|}
\hline & stIAT & $\begin{array}{l}\text { Arousal stIAT } \\
\text { pictures }\end{array}$ & $\begin{array}{l}\text { Genital } \\
\text { arousal }\end{array}$ & $\begin{array}{l}\text { Subjective arousal } \\
\text { video }\end{array}$ & $\begin{array}{l}\text { Disgust propensity } \\
\text { (DS-R) }\end{array}$ & $\begin{array}{l}\text { Disgust propensity } \\
\text { (DPSS-R) }\end{array}$ & $\begin{array}{l}\text { Disgust sensitivity } \\
\text { (DPSS-R) }\end{array}$ \\
\hline stIAT & - & & & & & & \\
\hline Arousal stIAT pictures & -.11 & - & & & & & \\
\hline Genital arousal & .29 & -.30 & - & & & & \\
\hline Subjective arousal video & .06 & .09 & $-.45^{*}$ & - & & & \\
\hline Disgust propensity (DS-R) & -.12 & .09 & -.13 & .34 & - & & \\
\hline Disgust propensity (DPSS-R) & -.18 & .00 & .01 & .29 & $.79 * *$ & - & \\
\hline Disgust sensitivity (DPSS-R) & -.18 & .35 & .07 & .13 & $.52 * *$ & $.52 * *$ & - \\
\hline Female SF & -.16 & -.12 & .27 & .10 & .03 & -.20 & -.04 \\
\hline
\end{tabular}

$S F$ sexual functioning

* Difference is significant at the .05 level (two-tailed); ** Difference is significant at the .01 level (two-tailed)

Table 8 Bivariate Correlations only for Men

\begin{tabular}{|c|c|c|c|c|c|c|c|}
\hline & stIAT & $\begin{array}{l}\text { Arousal stIAT } \\
\text { pictures }\end{array}$ & $\begin{array}{l}\text { Genital } \\
\text { arousal }\end{array}$ & $\begin{array}{l}\text { Subjective } \\
\text { arousal video }\end{array}$ & $\begin{array}{l}\text { Disgust propensity } \\
\text { (DS-R) }\end{array}$ & $\begin{array}{l}\text { Disgust propensity } \\
\text { (DPSS-R) }\end{array}$ & $\begin{array}{l}\text { Disgust sensitivity } \\
\text { (DPSS-R) }\end{array}$ \\
\hline stIAT & - & & & & & & \\
\hline Arousal stIAT pictures & -.23 & - & & & & & \\
\hline Genital arousal & -.13 & .10 & - & & & & \\
\hline Subjective arousal video & .20 & .43 & $.71 * *$ & - & & & \\
\hline Disgust propensity (DS-R) & .19 & .21 & $.51 *$ & $.50 *$ & - & & \\
\hline Disgust propensity (DPSS-R) & .13 & -.05 & .41 & .40 & $.58 * *$ & - & \\
\hline Disgust sensitivity (DPSS-R) & .32 & .17 & $.61 * *$ & $.66 * *$ & $.47 *$ & $.69 * *$ & - \\
\hline Male SF & -.24 & .20 & -.01 & .21 & .24 & .02 & -.13 \\
\hline
\end{tabular}

$S F$ sexual functioning

* Difference is significant at the .05 level (two-tailed); ** Difference is significant at the .01 level (two-tailed)

men. Study 2 showed a tendency suggesting that trait disgust was negatively associated with sexual functioning for both men and women. Future research with larger samples is required to arrive at more definitive answers on the question whether the association between disgust and sexual functioning is more prominent in women than in men.

Study 2 indicated that young women were more prone than men to experience disgust, as measured with both implicit and explicit measures. This finding is in line with previous research showing that women generally report higher levels of disgust than men, especially regarding sex (Druschel \& Sherman, 1999). Although women showed both relatively strong automatic sexdisgust associations and relatively high levels of disgust propensity, the correlational analyses indicated that both of these variables represent largely independent phenomena. Thus, at least in a non-clinical population, no evidence emerged to support the view that especially those with high disgust propensity would be at risk for developing (automatic) sex-disgust associations.

In addition, the overall correlational analysis showed no evidence for a relationship between trait disgust and the level of subjective or genital arousal that was elicited by the erotic video clips. However, when taking gender into consideration, it was found that specifically for men disgust sensitivity showed independent predictive value for the level of genital and subjective arousal. However, the direction of this relationship was opposite to our hypothesis as higher disgust sensitivity was associated with higher instead of lower levels of elicited sexual arousal. Clearly, this pattern of results does not support the view that enhanced trait disgust would be associated with lowered sexual arousability. The finding that men with relatively high disgust sensitivity scores displayed relatively strong sexual arousal that might be explained by assuming that perhaps people who are highly sensitive to disgust responses are also highly sensitive to other physical sensations such as the physical responses that are involved in sexual arousal. Since the level of arousal that was elicited in women was much smaller than in men this might have reduced the sensitivity of the present study for finding a similar relationship between disgust sensitivity and sexual arousal in women. Clearly, this interpretation is post hoc and should be tested further in future research.

It also may be the case that disgust, like performance demand and increased anxiety, has a facilitating effect in sexually functional men(Barlow, 1986). In sexually functional men, performance 
Table 9 Results of multiple regression analysis with (standardized) genital sexual arousal in women $(N=24)$ and men $(N=19)$ as to-bepredicted variable and different disgust dimensions as predictor variables

$\begin{array}{lllll}\mathrm{B} & \mathrm{SE} & \beta & t & p \\ \mathrm{~B} & & & \end{array}$

\begin{tabular}{lrrrrrr}
\hline Constant & -.556 & .291 & & -1.91 & .063 \\
Gender & -.026 & .135 & -.029 & -.191 & .849 \\
Disgust propensity (DPSS-R) & .001 & .022 & .012 & .064 & .949 \\
Disgust sensitivity (DPSS-R) & .036 & .018 & .290 & 1.96 & .056 \\
Gender $x$ disgust propensity & .001 & .046 & .036 & .032 & .975 \\
$\quad($ DPSS-R) & & & & & \\
Gender $x$ disgust sensitivity & -.075 & .051 & -1.39 & -1.48 & .148 \\
$\quad($ DPSS-R) & & & & & \\
\hline
\end{tabular}

$R^{2}=.084, \Delta R^{2}=.062(p=.056)$

Table 10 Results of multiple regression analysis with subjective sexual arousal in women $(N=24)$ and men $(N=19)$ as to-be-predicted variable and different disgust dimensions as predictor variables

\begin{tabular}{lrrrrrr}
\hline & B & SE B & $\beta$ & \multicolumn{1}{l}{$t$} & \multicolumn{2}{l}{$p$} \\
\hline Constant & 45.42 & 11.57 & & 3.93 & $<.001^{*} *$ \\
Gender & -32.72 & 4.66 & -.768 & -7.03 & $<.001^{* *}$ \\
$\begin{array}{l}\text { Disgust propensity } \\
\quad(D P S S-R)\end{array}$ & 1.23 & .571 & .236 & 2.16 & $.037^{*}$ \\
$\begin{array}{l}\text { Disgust sensitivity } \\
\quad(D P S S-R)\end{array}$ & 2.45 & 3.54 & .415 & .692 & .493 \\
$\begin{array}{l}\text { Gender } x \text { disgust } \\
\quad \text { propensity (DPSS-R) }\end{array}$ & 1.62 & 1.53 & .853 & 1.06 & .296 \\
$\begin{array}{l}\text { Gender } x \text { disgust } \\
\quad \text { sensitivity (DPSS-R) }\end{array}$ & -2.50 & 1.71 & -.978 & -1.46 & .152 \\
\hline
\end{tabular}

$R^{2}=.547, \Delta R^{2}=.547(p<.001) ; *$ Difference is significant at the .05 level (two-tailed); ** Difference is significant at the .01 level (twotailed)

demand enhances sexual arousal, whereas in sexually dysfunctional men it decreases sexual arousal. Further research is needed to investigate this potential cause of our finding, and needs to include both sexually functional and dysfunctional men.

It has been argued that the disgusting properties of sexual stimuli may interfere with the generation of sexual arousal (de Jong et al., 2013). Following this, we anticipated that for people who show a relatively strong tendency to associate sex with disgust, sexual stimulation would elicit less sexual arousal. However, although the correlations between stIAT performance and sexual arousal were in the predicted direction, they did not reach the conventional level of significance. Thus, at least in young adults without sexual problems, automatic sexdisgust associations seem no serious obstacle for the generation of sexual arousal. Perhaps, this was partly due to the strength of the sexual stimulation. Previous research has shown that both in men (Stevenson, Case \& Oaten, 2011) and women (Borg \& de Jong, 2012), sexual stimulation reduces the disgusting properties of sex-relevant disgust elicitors. Accordingly, also in the present study, sexual disgust may have been weakened or been taken away by the concurrently elicited sexual arousal. In line with the alleged inhibitory relationship between sexual arousal and disgust, sexual arousal may have become dominant in this group of sexually healthy individuals. It would be interesting to see in future research whether in the context of less intense stimulation the disgust eliciting properties might be more important especially in those with relatively strong automatic sex-disgust associations.

\section{Strengths and Limitations}

The strengths of the present study are that (1) it is unique as it incorporated both female and male study participants and (2) both implicit measures of cognitive and emotional responses (stIAT) and real-time genital and subjective sexual response measures were used.

One of the general limitations of examining sexual responses and psychological associations with sex in a laboratory environment pertains to external validity. It remains questionable whether the results would be the same in real-life circumstances. Also, it can be speculated that the stimuli used in the stIAT elicit more disgust responses than the sexual activities seen in the erotic video clips or in real-life sexual activities, which might have influenced the results. Furthermore, the results should be interpreted with caution due to the relatively small number of participants and the ascertainment bias that can occur with respect to sex research. Finally, patients with sexual dysfunctions were not included in this study, and so it remains to be determined if the results can be translated to clinical populations. To arrive at more final conclusions in this respect it would be important to replicate this study in a larger sample and by using various (also lower) levels of erotic stimulation.

\section{Conclusions}

Young adult women showed stronger sex-disgust associations and reported higher disgust propensity than men. Overall, no strong evidence was found to support the view that high trait disgust or relatively strong automatic sex-disgust associations would be linked with low sexual functioning and low sexual arousal in young adults without sexual problems. Thus, no evidence emerged to suggest that a generally enhanced disgust propensity/sensitivity or heightened sex-disgust associations are important risk factors in the development of sexual problems and dysfunctions. The current study can be considered a starting point for further research into the association of implicit associations, sexual arousal, and disgust. Further research should focus on other implicit sex-disgust measures like facial EMG. Improving our insight regarding the relationship between disgust and sexual functioning might also provide important clues to improve the conceptualization and treatment of sexual dysfunctions. 


\section{References}

American Psychiatric Association. (2013). Diagnostic and statistical manual of mental disorders (5th ed.). Arlington, VA: Author.

Barlow, D. (1986). Causes of sexual dysfunction: The role of anxiety and cognitive interference. Journal of Consulting and Clinical Psychology, 54, 140-148.

Barlow, D., Becker, R., Leitenberg, H., \& Agras, W. (1970). A mechanical strain gauge for recording penile circumference change. Journal of Applied Behavior Analysis, 3, 73-76.

Bluemke, M., \& Fiedler, K. (2009). Base rate effects on the IAT. Consciousness and Cognition, 18, 1029-1038.

Borg, C., \& de Jong, P. J. (2012). Feelings of disgust and disgust-induced avoidance weaken following induced sexual arousal in women. PLoS One, 7, e44111.

Borg, C., de Jong, P., \& Weijmar-Schultz, W. (2010). Vaginismus and dyspareunia: Automatic versus deliberate disgust responsivity. Journal of Sexual Medicine, 7, 2149-2157.

Brauer, M., de Jong, P., Huijding, J., Laan, E., \& ter Kuile, M. (2009). Automatic and deliberate affective associations with sexual stimuli in women with superficial dyspareunia. Archives of Sexual Behavior, 38, 486-497.

Chivers, M., Rieger, G., Latty, E., \& Bailey, M. (2004). A sex difference in the specificity of sexual arousal. Psychological Science, 15, 736744

Chivers, M., Seto, M., Lalumière, Laan, E., \& Grimbos, T. (2010). Agreement of self-reported and genital measures of sexual arousal in men and women: A meta-analysis. Archives of Sexual Behavior, $39,5-56$.

de Hullu, H., de Jong, P. J., Sportel, E., \& Nauta, M.H. (2011). Dysfunctional automatic associations with social activities in socially anxious adolescents. Behaviour Research and Therapy, 49, 518-522.

de Jong, P., \& Peters, M. (2009). Sexand the sexual dysfunctions: The role of disgust and contamination sensitivity. Washington, DC: American Psychological Association.

de Jong, P., van Overveld, M., \& Borg, C. (2013). Giving into arousal, or staying stuck in disgust? Disgust-based mechanisms in the development of sexual dysfunctions. Journal of Sex Research, 50, 247-462.

de Jong, P., van Overveld, M., Weijmar Schultz, W., Peters, M., \& Buwalda, F. (2009). Disgust and contamination sensitivity in vaginismus and dyspareunia. Archives of Sexual Behavior, 38, 244-252.

Druschel, B. A., \& Sherman, M. F. (1999). Disgust sensitivity as a function of the big five and gender. Personality and Individual Differences, 26(4), 739-748.

Fergus, T., \& Valentiner, D. (2009). The Disgust Propensity and Sensitivity Scale-Revised: An examination of a reduced-item version. Journal of Anxiety Disorders, 23, 703-710.

Geer, J. (1983). Measurement and methodological considerations in vaginal photometry. Paper presented at the meeting of the International Academy of Sex Research, Harriman, NY.

Greenwald, A., McGhee, D., \& Schwartz, J. (1998). Measuring individual differences in implicit cognition: The implicit association test. Journal of Personality and Social Psychology, 7, 1464-1480.

Greenwald, A., Nosek, B., \& Banaji, M. (2003). Understanding and using the Implicit Association Test: An improved scoring algorithm. Journal of Personality and Social Psychology, 85, 197-216.

Haidt, J., McCauley, C., \& Rozin, P. (1994). Individual differences in sensitivity to disgust: A scale sampling seven domains of disgust elicitors. Personality and Individual Differences, 16, 701-713.

Heiman, J. (1977). A psychophysiological exploration of sexual arousal patterns in females and males. Psychophysiology, 14, 266-274.
Hoon, P., Wincze, J., \& Hoon, E. (1976). Physiological assessment of sexual arousal in women. Psychophysiology, 19, 21-26.

Huijding, J., Borg, C., Weijmar-Schultz, W., \& de Jong, P. J. (2011). Automatic affective evaluation of sexual penetration in women with vaginismus and dyspareunia. Journal of Sexual Medicine, 8, 806-813.

Janssen, E., \& Everaerd, W. (1993). Determinants of male sexual arousal. Annual Review of Sex Research, 4, 211-245.

Laan, E., Everaerd, W., \& Evers, A. (1995). Assessment of female sexual arousal: Response specificity and construct validity. Psychophysiology, 32, 476-485.

Laumann, E., Paik, A., \& Rosen, R. (1999). Sexual dysfunctions in the United States: Prevalence and predictors. Journal of the American Medical Association, 281, 537-544.

Oaten, M., Stevenson, R., \& Case, T. (2009). Disgust as a diseaseavoidance mechanism. Psychological Bulletin, 135, 303-321.

Palti, Y., \& Bercovici, B. (1967). Photoplethysmographic study of the vaginal blood pulse. American Journal of Obstetrics and Gynecology, 97, 143-153.

Payne, K., Binik, Y., Amsel, R., \& Khalifé, S. (2005). When sex hurts, anxiety and fear orient attention towards pain. European Journal of Pain, 9, 427-436.

Rosen, R., Brown, C., Heiman, J., Leiblum, S., Meston, C., Shabsigh, R., et al. (2000). The Female Sexual Function Index (FSFI): A multidimensional self-report instrument for the assessment of female sexual function. Journal of Sex and Marital Therapy, 26, 191-208.

Rosen, R., Riley, A., Wagner, G., Osterloh, I., Kirkpatrick, J., \& Mishra, A. (1997). The International Index of Erectile Function (IIEF): A multidimensional scale for assessment of erectile dysfunction. Urology, 6, 822-830.

Rozin, P., Nemeroff, C., Horowitz, M., Gordon, B., \& Voet, W. (1995). The borders of the self: Contamination sensitivity and potency of the mouth, other apertures and body parts. Journal of Research in Personality, 29, 318-340.

Sintchak, G., \& Geer, J. (1975). A vaginal plethysmograph system. Psychophysiology, 12, 113-115.

Stevenson, R., Case, T., \& Oaten, M. (2011). Effect of self-reported sexual arousal on responses to sex-related and non-sex-related disgust cues. Archives of Sexual Behavior, 40, 79-85.

van Overveld, M., De Jong, P., \& Peters, M. (2010). The Disgust Propensity and Sensitivity Scale-Revised: Its predictive value for avoidance behaviour. Personality and Individual Differences, 49, 706-711.

van Overveld, M., De Jong, P., Peters, M., Cavanagh, K., \& Davey, G. (2006). Disgust propensity and disgust sensitivity: Separate constructs that are differentially related to specific fears. Personality and Individual Differences, 41, 1241-1252.

van Overveld, M., de Jong, P. J., Peters, M. L., \& Schouten, E. (2011). The Disgust-Scale-R: A valid and reliable index to investigate separate disgust domains. Personality and Individual Differences, $51,325-330$.

van Overveld, M., De Jong, P., Peters, M., van Lankveld, J., Melles, R., \& Ter Kuile, M. (2013). The Sexual Disgust questionnaire: A psychometric study and first exploration in patients with sexual dysfunctions. Journal of Sexual Medicine, 10, 396-407.

Wigboldus, R., Holland, R., \& van Knippenberg, A. (2005). Single Target Implicit Associations, Unpublished manuscript.

Wincze, J., Vendetti, E., Barlow, D., \& Mavissakalian, M. (1980). The effects of a subjective monitoring task in the physiological measure of genital response to erotic stimulation. Archives of Sexual Behavior, 9, 533-545. 